\title{
The White Paper for Vulnerable Children and the Munro Review of Child Protection in England: a comparative critique
}

\section{Ian Hyslop}

Ian Hyslop is currently employed as a lecturer in the School of Counselling, Human Services and Social Work at Auckland University. He has worked as a statutory social worker and supervisor for 20 years in South and West Auckland. Prior to his current appointment, Ian worked at Unitec in Auckland where he designed and taught Child Protection Studies courses to both undergraduate and postgraduate students. Ian is passionate about the identity of social work and how, and in whose interests, the practice of social work will be defined in the 21st century.

\section{Abstract}

The apparent understandings of knowledge for child protection social work practice which inform the New Zealand White Paper for Vulnerable Children are contrasted with the views expressed in the Munro Review of Child Protection in England. It is argued that the rational-technical view of child protection practice knowledge critiqued in the Munro Review is the driving influence in the White Paper. It is further suggested that the White Paper is underpinned by neoliberal conceptions of individuated responsibility which conflict with the socially situated and relational understandings which are native to the theory and practice of social work. Consequently, the socio-technical social work practice knowledge form recognised and promoted in the Munro Review is marginalised in the White Paper. It is also argued that the failings of the child protection system in Aotearoa New Zealand are more appropriately associated with political and managerial misapprehension of knowledge for competent practice than with the shortcomings of social work as a vehicle for effective child protection. It is suggested that it is high time for the social work voice to be rediscovered and reasserted if effective, relationally engaged, practice with high needs children and their families is to be developed and promoted in politically challenging times.

\section{Introduction}

This article contrasts the view of social work knowledge evident in the recent New Zealand Government White Paper for Vulnerable Children with that of the Munro Review of Child Protection in England. Both of these policy documents were developed against a background of perceived failings in their respective child protection systems, particularly the deaths of vulnerable children. Very different prescriptions are arrived at in relation to the reform of child protection practice. ${ }^{1}$ I will argue that this divergence can be linked with differing

1 It is recognised that there are significant and complex differences as well as significant commonalities between the two jurisdictions in relation to the political context surrounding the production and implementation of these reviews. 
understandings of social work in the child protection field, particularly in relation to the nature of the knowledge applied and generated in practice.

\section{The White Paper}

The analysis which is provided in the White Paper is influenced by discourses of populist moral panic, medico-scientific understandings of the causes and consequences of child abuse, and managerial prescriptions for narrowly conceived production efficiency and risk reduction. These influences are fused within the broader rubric of a neoliberal social policy agenda. An underlying focus on the shortcomings of social work practice and the danger posed by the disenfranchised citizens with whom social workers routinely engage obscures the damage caused by the contemporary managerial regimes which are applied in the measurement and management of statutory practice. This orientation also diverts attention from the social damage wrought by a dominant political and economic ideology which privileges the private accumulation of capital at the expense of equality, inclusion, and social cohesion (Gray \& Webb 2013). For example, the juxtaposition of early contact observations of Maori parenting as warm and indulgent with the current comparative vulnerability of Maori children does not reach to any depth exploration of the socio-economic reasons for this transformation. In fact reference to the significance of Maori social structure and values is selective, superficial and clichéd. In a manner consistent with the historical relationship between the Crown and Maori, responses to the White Paper, particularly in relation to its uneasy fit with the concurrent Whanau Ora policy programme, are likely to involve elements of both resistance and strategic cooperation. However, exploration of these issues is not the focus of this paper. The central aim is to scrutinise understandings about the nature and function of social work which inform the White Paper in comparison to the Munro Review.

I have previously argued that contemporary developments in child protection social work have not taken sufficient account of the nature of social work practice 'knowledge': the communicative, interactive, 'context-informed' knowing and doing which is generated and applied in the doing of social work with children and families (Hyslop 2009). As Ferguson (2011) has recently observed, an excessively rational-technical approach has led to:

... a curious absence from a great deal of social work and child protection literature, policy and discussions about practice of any considered attention to the core dynamic, experience and methods of doing the work (p. 4).

Regrettably this trend is continued in the White Paper. The raft of initiatives proposed is primarily informed by a rational-technical, or instrumental, view of knowledge for practice. I will suggest that professional social work judgement has been marginalised as a consequence - reduced to the realm of procedural compliance and recording practices. Contrary to Ferguson's (2004: 7) assertion that the future of social work may be linked with a deeper understanding of the experience of child protection practice, the White Paper decentres social work, along with vital elements of the knowledge which informs and sustains its practice. Aspects of social work practice are doubtless of a technical character, but the application of knowing in practice, and the creation of understandings 'with' clients in the process of practice, involves a knowledge form of a different order. In terms of practice quality, and ultimately in terms of outcomes for the children and families who are served by the child protection system, it is unfortunate - arguably tragic - that social work practice 'knowing' is not better understood and valued within the policy realm. 
This 'decentring' of social work is not surprising given that much of the thrust of the White Paper is ostensibly concerned with widening the protective responsibilities of individuals, families, communities, business and 'front-line' professionals across Health, Education, Welfare and other sectors of government. However, there is also something of a paradox at work. Measures to improve the efficiency of an overloaded child protection system in the last two decades have led to failings in that system, as evidenced in the Munro Review analysis of comparable developments in England. My concern is consistent with Butler and Drakeford's (2005) suggestion that the 'personal and human elements' of social work in Anglophone jurisdictions have been diminished by ' ... a double discursive alliance of scientism and managerialism' (p.643). Child protection social work may be failing but my argument is that this is primarily due to a managerial focus which does not adequately recognise the nature of practice in this uncertain and critical field - what social work in child protection should be and could be. My further concern is that the White Paper simply prescribes more of the same, albeit with a risk prediction data-base.

\section{Politics and ideology}

First it is important to recognise that there are significant ideological dimensions to the White Paper. The statement from the Minister of Social Development which introduces the document clearly carries a political intent, signalling a 'tough' response to child abuse and child abusers:

Though I acknowledge the pressure that financial hardship puts on families, that is never an excuse to neglect, beat, or abuse children. Most people in such circumstances do not abuse their children, and I cannot tolerate it being used as a justification to do so. (Bennett, Vol.1, p.2)

The notion of 'excuse' is significant. It seems that the concepts of explanation and justification have been ingenuously muddled. The implication, in a neoliberal political climate, is that social understandings detract from the requisite emphasis on individuated responsibility. In my opinion this back-grounding of the need to comprehend the social context of individual and family behaviour undermines the foundations of social work practice knowledge $\left(\mathrm{O}^{\prime}\right.$ Brien 2001; Gray \& Webb 2013). For example, the experience of poverty can be related to a variety of factors which strain family relationships and resources. These factors can contribute to child maltreatment and a variety of other negative outcomes for children. Accordingly such insight should inform, in part, our understandings of child protection practice.

The '... evidence and detailed policy rationale' for the White Paper is developed in Volume 2 (p. 9). There is lengthy exploration of the concept of vulnerability with reference to research into the causes and effects of child maltreatment. The psychological and behavioural dimensions of vulnerability and maltreatment are emphasised. Parental pathology is a central focus. Science-centred research knowledge is privileged and selectively utilised. For example, an emphasis on the damaging consequences of early neglect experience for the infant brain is not balanced by consideration of recent neuroscience which indicates greater plasticity and resilience than has previously been recognised (Wastell \& White 2012). There are two key points I wish to emphasise. First, science is never static and secondly insight into the effects of abuse will not definitively tell you how best to intervene with children and families generally or particularly. This knowledge is embedded rather in the uncertain and ambiguous territory of child protection social work practice. 
As suggested, the White Paper pays minimal attention to the socio-political context of child protection. Specifically, there is no analysis of the relationship between the suggested group of dangerous families and the socio-economic form within which this apparent underclass is produced. The influence of social inequality - the structural reasons for the increasingly unequal distribution of material and emotional hardship - is absent from the text. Such references as there are tend to refer back to the panacea of paid work and the danger of welfare dependency (Bennett 2012: 54). The dearth of overt socio-political analysis is unsurprising, however it is important to recognise that there are underlying political choices in the emphases that are chosen. Material hardship and financial stress could, for instance, be constructed as unifying concepts in relation to child vulnerability rather than simply recorded as a minor sub-heading amongst a list of contributing factors. Anti-social behaviour, criminality, addiction and mental health issues are all disproportionately prevalent / visible amongst the economically disadvantaged.

\section{Risk and surveillance}

Aside from the creation of multi-disciplinary Children's Teams, the most significant practice initiative in the White Paper is the proposed development of a sophisticated risk predictor tool in order to identify an estimated 20 to 30,000 high risk children / families. This tool is linked with the creation of a 'Vulnerable Kids Information System' designed to track multi agency work with such families. Many elements of this 'new' approach are perhaps not so new. In fact the practice of distancing child abusing families from the respectable classes which, according to Ferguson (2004), historically structures social work with children and families, seems to be alive and well:

Better and smarter use of the information government already holds can help us focus on children who are really vulnerable, reducing the chances that a child in need will be missed, or that an everyday family will be incorrectly labelled as being at risk (Bennett 2012: Vol.1: 11)

Clearly 'we' everyday people are exempt from the indignity of such surveillance and the stigma of being seen as in need of social support or assistance. The scarecrow threat of statutory social workers is presented to those who are deemed to be both vulnerable and resistant to the involvement of state authority:

Where parents refuse to participate in the process, and where concerns are sufficient to indicate that children may be in need of care and protection, the option of referrals to Child, Youth and Family will remain. Parents will be made aware of this possibility. (Bennett 2012: Vol.1: 64).

It seems that the notion of developing knowledge (and planning) 'with' vulnerable families is secondary to discovering, and sharing, knowledge 'of' dangerous families, and planning 'for' intervention in the lives of vulnerable children.

\section{Social work practice knowledge}

The knowledge generated and applied in the practice of social work can be linked with wider aspects of social humanist philosophy embedded within the critical enlightenment tradition (Pease 2010). Social work is historically concerned with the potential for individuated redemption which rests, in turn, upon a premise of shared human worth (Goldstein 1990). The impetus of this knowledge frame is to humanise and include rather than demonise; to 
engage, understand and change perceptions rather than to detect and punish (Philp 1979). Effective social work practice involves communicative engagement with vulnerable children and their families. This locus of practice generates an awareness of social inequality and power imbalances. It sustains an 'individuated' intervention focus that balances risk with empowerment and inclusion. In this way the failings of abusive parents are placed simultaneously within a broader frame of social analysis and a more specific personal context.

Crucially, although a belief in social inclusion can be seen to underpin social work practice, it is far from a naïve faith. Practice experience also generates an awareness of human frailty and barriers to change. Child safety is necessarily paramount in child protection practice. The dual structure of the professional role requires effective engagement with adults and also strategies which guard against workers being 'captured' by such relationships. Within this process the subjective 'possibility' of reform - individuated change - is weighed alongside the knowledge claims associated with objective / scientific 'probability'. The following excerpt from the White Paper signals a position that is at variance with the precepts of this knowledge form:

Another potential restriction is that when a child has been removed from a home due to serious abuse at the hands of a parent, the existence of a child abuse prevention order could mean that another baby born into that situation is removed from the parents' care. Though the Court will make the decision about whether to remove the child there is an expectation that the child will be removed from the care of the parents, unless it can be shown that this is not in the best interests of the child. (Bennett 2012, Children's Action Plan).

There is a subtle but significant shift towards a presumption of incapacity for change in adult behaviour. This position can be instructively contrasted with the more balanced stance of 'respectful scepticism' identified by the London Directors of Children's Services and reproduced in Part One of the Munro Review:

Underlying all the work that social workers do is a value base which incorporates an approach where empathy and warmth are central, where respectful scepticism is a priority and which is based on a holistic view of the child and family. Social workers act as advocates and at the core is the preservation of human rights for children, and families, where this is not in conflict. (Munro 2010: 55).

\section{Evidence, technocracy and measurement}

The friction which exists between relational engagement and assessment processes associated with scientific classification and measurement is an underlying source of tension in contemporary practice. The White Paper is preoccupied with tools and programmes which can produce quantifiable evidence of efficient and effective reductions in problematic behaviour. This is an essentially reductive approach to social work and a minimalist view of the knowledge which supports creative practice. Pease (2010) links the current ascendancy of evidence-based practice with the scientific paradigm, suggesting that this phenomenon needs to be understood within the context of a wider, politically situated, debate about the nature and credibility of differing forms of knowing in and for social work. As Gray and McDonald (2006) suggest, 'the emergence of evidence-based practice must be appreciated within the context of neoliberalism, manifest in the various administrative strategies of New Public Management' (p.8). The notion of 'evidence' is often conflated with the managerial imperative to measure the efficiency and effectiveness of service delivery in terms of the relationship between investment and outcomes. 
The vision of the White Paper involves cross-disciplinary 'common assessment' processes and standardised intervention programmes - specifically parenting programmes and intensive home visiting regimes. Presumably the processes of relational engagement, shared knowledge generation and empowerment which are critical to social work are likely to be practised in the context of these targeted social support services, but there is no acknowledgement or exploration of this in the White Paper. The White Paper does assert that tools such as the risk predictor instrument will inform rather than replace professional judgement, but there is little or no reference to what engaged professional judgement might consist of. Although context is seen to be relevant to the construction of risk profiles, the White Paper promotes a procedurally and technologically dominated view of knowledge for social work practice. The fact that practice engages with people rather than profiles appears to be largely overlooked. ${ }^{2}$ The standardisation and measurement (commodification) of practice does strengthen managerial control and accountability, but it also potentially undermines the social work predilection to adapt intervention to the requirements of specific situations: to meet the needs of vulnerable children and families in safe and flexible ways.

The restructuring of services which the White Paper outlines clearly implies that the child protection services provided by Child, Youth and Family have not been as effective as needed. Ironically the report also asserts that, '... Child, Youth and Family's performance has constantly improved over the last six years':

Nearly all performance targets have been achieved in recent years, and Child, Youth and Family has significantly improved the speed and efficiency of its child protection screening, assessments, and investigations. (Bennett Vol.2: 108).

In other words the performance has been improving, but the outcomes have been deteriorating. This paradox appears to have been overlooked. There is no overt consideration given to the implication that the assumed relationship between efficiency measurement and social work practice may in fact have been misinformed and counter-productive. While the need to improve the quality and depth of child protection practice is accepted in the White Paper there is no acknowledgement that the managerial cure may well have disabled the patient. There is no recognition that this increase in speed and efficiency may have concealed, and fuelled, a reduction in the engaged practice which is vital to successful child protection work and to social work more generally. Compliance-driven social work undermines the reflection which safe, and context-responsive, practice requires.

Chapter Six of Volume 2 (p.104) purports to set out, '...how the Government will improve child protection services, particularly in relation to strengthening the quality of social work practice'. There is however very little reference to what quality practice is comprised of beyond some restructuring of assessment and recording processes. Apart from intent to refocus Care Services, increase the efficiency of Family Group Conferences and increase the proportion of registered social workers, the report merely refers back to the structural and procedural changes previously outlined. At this point it is valuable to consider and contrast the approach to social work knowledge evident from the Report/s of the Munro Review. ${ }^{3}$

2 Parton (2008) questions whether the form of knowledge for social work may be undergoing a fundamental discursive shift from the 'social' to the 'informational': towards a de-humanised modernity dominated by the logic of the algorithm. It is suggested that non-human technologies, informed by the binary logic of the database, are increasingly being used to construct individuals against preconceived risk indices. 


\section{Munro Review of Child Protection in England}

This exercise was conducted in response to similar political concerns about the effectiveness of child protection practices. Although the exercise was not commissioned as a direct response to a child abuse tragedy, the public 'scandal' surrounding the death of 'Baby Peter' in Haringey, North London, in 2007 contributed significantly to the context of the review (Parton, 2012). It is the most recent in a series of reviews concerning perceived failings of the child protection system in the U.K., dating from the 1973 Maria Colwell enquiry. The emphasis of the Munro Review differs in important ways from the White Paper. There are various contextual reasons for this, but perhaps the most significant of these can be traced to the terms of reference and leadership of the review process. The review was commissioned by Government and undertaken independently by Professor Eileen Munro of the London School of Economics and Political Science, a distinguished academic with considerable practical experience of child and family social work. The Final Report, completed in May 2011, was prefigured by two interim reports. As stated in the executive summary of the final document '.... central question was 'what helps professionals to make the best judgements they can to protect a vulnerable child?' ' (p.6). As a consequence, support for the development of sound professional judgement in social work practice was a focal point for the review process.

A further starting point in the English setting was the apparent lack of improvement in child protection systems despite the numerous previous enquiries, recommendations and structural changes. Munro takes a systems approach to analysing the functioning of child protection services, drawing on the theoretical insight that well intentioned changes within complex systems can have unforeseen consequences. In contrast to the White Paper, the first of these reports (Part One) signals immediate and explicit concern with the deleterious effects of an over-standardized system dominated by performance expectations and inspection, particularly the relationship between prescriptive time-scales for assessing the needs of children and the quality of practice provided:

Earlier reforms have also contributed to the growing imbalances in that they have tended to focus on technical solutions - increasing rules, more detailed procedures, more use of ICT while giving less attention to the skills to engage with families, the expertise to bring about enduring impacts in parenting behaviour, and the organizational support that enables social workers to manage the emotional dimensions of this work without harming their judgement or their overall well-being (Munro 2010: 7).

The efforts to improve practice have not addressed all the weaknesses in practice and have tended to focus mainly on the process of case management, increasing regulation and standardisation of assessment frameworks. Difficulties such as forming working relationships with families, asking challenging questions to really understand the family's history and current situation, keeping an objective view on what is happening and coping with the demands of the work have received less attention (Munro 2010: 12).

Munro identifies the fundamentally uncertain and relational nature of child protection work and suggests that the 'scientific' (rational-technical) understandings that have

The three consecutive Reports which comprise the Munro Review are referred to as Part One, the Interim Report, and the Final Report within the text of this article. 
under-pinned managerial reform have failed to take adequate account of the non-linear knowledge form that is inherent to social work practice:

In the extensive reforms that have shaped today's work environment, the professional account of social work practice in which relationships play a central role appears to have been stifled and replaced by a managerialist account that is fundamentally different. The managerialist approach has also been called a rational-technical approach ... (Munro 2011a: 36).

In social work practice the application of 'evidence' involves a flexible/discretionary matching of intervention to the needs of clients in their particular circumstances. The rational-technical knowledge schema is contrasted with what Munro describes as a 'socio-technical' approach to understanding child protection. This analysis accepts that although social work practice knowledge contains dispassionate/scientific elements it is also essentially 'social' in character: it is relational, communicative and contextual - influenced by socially configured relations of power:

Good social work practice requires forming a relationship with the child and family and using professional reasoning to judge how best to work with parents (Munro 2011a: 11).

According to Munro a socio-technical approach, '... does not underestimate the value of rigorous analytical thinking, but argues for a balance of abstract analysis and consideration of human relations' (Munro 2011a: 16). This conceptual position resonates with my own experience of practice. Child protection social workers balance objective knowledge with subjective client-centred understandings of social possibility. It is also consistent with the notion that outcomes are co-produced through an interactive relationship between practitioners and clients:

Taking a 'socio-technical' approach to child protection points to the work being essentially 'social' even though there is a place for technical aids; it deals with people not with objects (Munro 2010: 17).

The socio-technical concept allows for practice knowledge that is generated through processes of communicative engagement, including elements of intuitive and empathetic understanding. The Munro Review perceives that institutional risk anxiety is liable to generate convoluted recording regimes, compliance-driven models of assessment and an unduly rigid preoccupation with timeliness as a measure of practice quality. Most significantly, such approaches are apt to lose sight of the primary need to support practitioners to develop and apply their professional knowledge in this highly demanding area of social work practice. The following excerpt from the Interim Report illustrates the multiple dimensions of awareness that practitioners bring to this task:

When social workers are talking to a child and their family in their home, they are drawing on several sources of information and making swift decisions and changes as the interview progresses. Their conscious mind is paying attention to the purpose of their visit; at an intuitive level they are forming a picture of the child and family and sensing the dynamics in the room, noting evidence of anger, confusion or anxiety ... It will be argued that previous reforms have concentrated too much on the explicit, logical aspects of reason and this has contributed to a skewed management framework that undervalues intuitive reasoning and emotions and thus fails to give appropriate support to those aspects (Munro 2011a: 35).

The above description mirrors the picture of social work in action provided by practitioners 
interviewed for my recent doctoral research project. This is graphically illustrated in the following excerpt taken from an interview with a child protection social worker:

But really there's more to it - you go in at 150 mile an hour, even though you're talking to them and saying, 'Oh, that's nice, that's good, so how's things going with baby? Did you take baby to Plunket?' And all the time you're looking - you're hearing - (...pause...) - you're 'smelling' you've got to be up with the play. It's normal. We just know it as something normal. Even where you sit when you go into a house. I always make sure before I sit I know where the back door is or the front door or if there's a ranch slider. I always make sure I know where it is and I try and sit close to one of them because I don't know what to expect. And I'll have a 'look-see' who's at the back door, the ranch slider door before I sit. All those things - a lot of stuff going on - and counting how many adults in the house (Italic emphasis added) (Hyslop 2013: 119).

Munro perhaps most succinctly encapsulates the flaw of giving undue primacy to rational-technical understandings of child protection in suggesting that it '... has fostered a view that the more important part of social work is carried out on a computer'. She goes on to stress that from the point of view of children and their parents '... the most important activity takes place when social workers meet children and families, try to communicate with them, and help them to change' (Munro 2011b: 87).

\section{Implications for reform}

The Munro Review associates negative outcomes with an overly centralised and bureaucratised system, emphasising that, '...the centrality of forming relationships with children and families to understand and help them has been obscured' (Munro 2011b: 8). Accordingly, the focus for reform becomes the development of professional social work knowledge and expertise - and creating systems which best support this process. The Final Review Report identifies various inter-related components of practice expertise and considers appropriate educational and organisational reforms. Relationship skills are identified as central to the key task of communicating with children and adults. Analytical skills are identified as a function of experience and reflection (Munro 2011b: 87), and the place of intuitive and emotional responses in the reasoning process is acknowledged (Munro 2011b: 89-90). The crucial role of supervision is underlined. The Final Report also pays significant critical attention to the concept of evidence-based practice. The approach taken is a further application of a socio-technical understanding of practice knowledge. Munro's vision of evidence-based practice highlights rather than de-emphasises the importance of professional judgement. In practice the application of evidence involves a flexible/discretionary matching of intervention to the needs of clients in their particular circumstances:

Here it is used in the broader sense of drawing on the best available evidence to inform practice at all stages of the work and of integrating that evidence with the social worker's own understanding of the child and family's circumstances and their values and preferences. It is '...not simply a case of taking an intervention off the shelf and applying it to a child and family' (Munro, 2011b, p.92).

It is important not to overly sanctify the Munro Review, as pleasing as it is to see some recognition of the policy relevance of knowledge developed in and through the practice of social work in this demanding and sometimes unforgiving field. Parton (2012) has pointed out some disturbing synergies between the emphasis on a return to greater professional discretion and the political agenda on the Liberal - Conservative coalition in the U.K. As 
Parton (2012, p.162) suggests, the 'success' of the review is likely to 'depend on social, cultural and political factors well beyond its influence'. The combined effect of an emphasis on authoritative child protection and the reduction of broader state-mandated services for children and families within a discourse of fiscal austerity and neoliberal notions of individuated blame may well have draconian consequences.

\section{Comparison and reflection}

The foregoing discussion has been used to exemplify the critical contemporary relevance of an understanding - or a misapprehension - of practice knowledge for the future development of child protection work and to social work more generally. As noted, there are differences in the genesis, focus and process which produced these two reports, not to mention the distinctions of scale, culture and history between the two jurisdictions. Also, there are elements of commonality within the review findings, such as the need for better interdisciplinary coordination and an imperative to give more concerted attention to the needs and views of children. However, given my interest in the benefits (principally for children and families in need) that may flow from a deeper insight into the nature of social work practice ' $k$ nowing', it is difficult to see the White Paper as anything other than an opportunity lost. The White Paper privileges a rational-technical view of child protection practice which affords only a partial view of practice knowledge and expertise. In my opinion this distorted vision is responsible for many of the shortcomings of the contemporary child protection system in Aotearoa New Zealand. By contrast, much of the content of the Munro Review exemplifies the progressive developmental insights that can be derived from an appreciation of the knowledge applied in, and generated through, the process of social work in child protection.

It is ironic that social work has been de-emphasised in the White Paper approach to child abuse since it appears that child protection social work has been convicted of political and managerial failings that are not of its own making. It may be the case that the role and significance of practice knowledge has not been adequately valued in the Aotearoa New Zealand context because it has been poorly understood within the policy realm. I would also argue that the implicit neoliberal political ideology which underlies the White Paper reforms is at odds with the inclusive and relational knowledge form that is inherent to the theory and practice of social work. For the social work voice to be recognised - and for the benefits of engaged and relational practice in social work with vulnerable children and families to be more fully realised - the nature of social work practice knowledge needs to be more effectively articulated. Houston (2001) reinforces the somewhat chilling caution attributed to Aldridge:

...Aldridge (1996) reminds us that social workers in a postmodern world need to abandon their equivocating stance over their expertise and develop a more confident set of intellectual skills.

To do otherwise is to atrophy into a forgotten profession (Houston 2001: 224).

A social, or 'socio-technical', analysis of practice knowledge makes allowance for a kind of 'knowing' that deviates from (and subverts) rational-technical practice models and theoretical understandings. Despite the procedural regimentation of practice, social workers can and do actively resist simplistic discourses of individual pathology and child rescue. As Gray and Webb (2012: 14) suggest, social work is inevitably 'about how the personal connects to the political'. Engaged practice supports an individuated view of social justice - social workers 'see' objective social disparity and structural disadvantage while engaging with the com- 
plexity of subjective circumstance and differential understandings of those circumstances. Child protection social workers carefully balance risk with possibility.

This article has set out to contribute to the task of revealing where, '...the green shoots of a more engaged practice' (Garrett 2007) may be found in the changing socio-political context of 21st century Aotearoa New Zealand. The generative paradox is that the more constrained, regulated and risk averse statutory social work becomes, the more the disparity between practice design and the socially located understandings applied and generated in practice is brought into focus. Militant energy for the development of critical social work is generated by the imposition of technocratic and exclusionary practices which characterise neoliberal governance of the social (Gray and Webb 2013). Increasingly, social work practitioners and academic educators are exploring ways to reinvigorate the identity of social work and to assert what it is that the social work voice has to contribute to the development of social policy and social practice.

\section{References}

Bennett, P. (2012). The white paper for vulnerable children. Retrieved from Ministry of Social Development website: https / / www.childrensactionplan.govt.nz / the-white-paper.

Butler, I., \& Drakeford, M. (2005). Trusting in social work. British Journal of Social Work Special issue 35(5): 639-653.

Ferguson, H. (2004). Protecting children in time: Child abuse, child protection and the consequences of modernity. Basingstoke, UK: Palgrave Macmillan.

Ferguson, H. (2011). Child protection practice. Basingstoke, UK: Palgrave Macmillan.

Garrett, P. (2007). Making social work more Bourdieusian: Why the social work professions should critically engage with the work of Pierre Bourdieu. European Journal of Social Work 10(2): 225-243.

Goldstein, H. (1990). The knowledge base of social work practice: Theory, wisdom, analogue, or art? Families in Society 7(1): 32-42.

Gray, M., \& McDonald, C. (2006). Pursuing good practice: The limits of evidence-based practice. Journal of Social Work 6(1): 7-20.

Gray, M., \& Webb, S. (Eds,) (2013). The new politics of social work. Basingstoke, UK: Palgrave Macmillan.

Houston, S. (2001).Transcending the fissure in risk theory: Critical realism and child welfare. Child E Family Social Work 6(3): 219-218.

Hyslop, I. (2009). Child protection policy and practice: A relationship lost in translation. Social Policy Journal of New Zealand 34(April): 62-72.

Hyslop, I. (2013). Social work practice knowledge - An enquiry into the nature of the knowledge generated and appllied in the practice of social work. Unpublished PhD thesis: Massey University, New Zealand.

Munro, E. (2010). Review of child protection in England: Part One: A systems analysis. Retrieved from Department of Education website: https:/ / www.gov.uk/government/uploads/system/uploads/attachment_data / file/175407/ TheMunroReview-Part_one.pdf.

Munro, E. (2011a). Munro review of child protection: Interim report - The child's journey. Retrieved from Department of Education website: https://www.gov.uk/government/publications/munro-review-of-child-protectioninterim-report-the-childs-journey

Munro, E. (2011b). Review of child protection in England: Final report: A child-centred system. Retrieved from http:/ / www.official- documents.gov.uk/document/cm80/8062/8062.pdf.

O'Brien, M. (2001). Social work in context: Economics, organization, politics, and ideology. In M. Connolly (Ed.), New Zealand social work: Contexts and practice (pp. 44-54). New York, NY: Oxford University Press.

Parton, N. (2008). Changes in the form of knowledge in social work: From the 'social' to the 'informational'? British Journal of Social Work 38(2): 253-269.

Parton, N. (2012). The Munro Review of Child Protection: An appraisal. Children in Society 26(2): 150-162.

Pease, B. (2010). Challenging the dominant paradigm: Social work research, social justice and social change. In I. Shaw, K. Briar-Lawson, J. Orme, \& R. Ruckdeschel (Eds.), The SAGE handbook of social work research (pp. 98-113). Los Angeles, CA: Sage.

Philp, M. (1979). Notes on the form of knowledge in social work. Sociological Review 27(1): 83-111.

Wastell, D., \& White, S. (2012). Blinded by neuroscience: Social policy, the family and the infant brain. Families, Relationships and Societies 1(4): 397-414. 